\title{
Dental implant success in irradiated jaws: A retrospective study
}

Kıvanç Bektaş-Kayhan*,Erkan Sancakl, Ali Balık, Emrah Baca, Tamer Çelakıl *istanbul University, Faculty of Dentistry, Department of Oral and Maxillofacial Surgery ** Istanbul University, Faculty of Dentistry, Department of Maxillofacial Prosthesis

\section{INTRODUCTION}

Head and neck cancer patients (HNCPs) usually need serious oro/dental constructive support after the cancer therapy. Although radiation -especially in curative doses- has a negative influence on osseointegration, dental implants are trustful partners in dental rehabilitation of these patients for many years.

\section{OBJECTIVES}

Our aim here to present the success of dental implants even in high radiation doses (>50 Gy) of HNCPs.

\section{MATERIALS AND METHODS}

The data of HNCPs who were referred to oral and maxillofacial surgery clinic from 2011-2017 were reviewed for inclusion criteria's: 1. Receiving total dose of radiotherapy $>50 G y, 2$. Performed dental implant surgery by the author (KBK), 3. Prosthetic rehabilitation was completed at least 6 months ago. The criteria were fulfilled by 53 patients ( 19 female, 34 male) with the mean age of 54.03. The success and complications of dental implants were evaluated.

\section{RESULTS}

Mean follow up time was 32 months. 176 implants were inserted, and long-term success rate was calculated as $94,9 \%$. In total, 9 implants were lost. Only 2 cases of osteoradionecrosis were evident with successful recovery in 4-10 months.

Table 1. Distribution of implants placed in jaws and success rates

\# of implants \# of implants Success \% placaed failed

\begin{tabular}{c|c|c|c|}
\hline Maxilla & 78 & 6 & 92.3 \\
\hline Mandible & 98 & 3 & 96,9 \\
\hline Total & 176 & 9 & 94,9
\end{tabular}

\section{CONCLUSION}

1.The osseointegrated implant supported dental rehabilitation should be considered as reliable partners in dental rehabilitation of HNCPs. Under the special precautions, they are successful even in high doses of radiation.

2.Today, oral and maxillofacial surgeon and prosthodontists are inseparable part of oncology team with a positive impact to head and neck cancer patients' quality of life.
Table 2. Distribution patient group due to location of the tumor and dose of radiation

\begin{tabular}{|c|c|c|}
\hline $\begin{array}{c}\text { \# OF } \\
\text { PATIETS } \\
(\%)\end{array}$ & $\begin{array}{c}\text { LOCATION OF } \\
\text { THE TUMOR }\end{array}$ & $\begin{array}{c}\text { TOTAL DOSE } \\
\text { OF } \\
\text { RADIATION } \\
\text { (GY) }\end{array}$ \\
\hline $16(30.2 \%)$ & Nasopharynx & $66-72$ \\
\hline $9(17 \%)$ & Mobile Tongue & $50-64$ \\
\hline $8(15,1 \%)$ & Floor of mouth & $60-72$ \\
\hline $5(9,4 \%)$ & $\begin{array}{c}\text { Retromolar } \\
\text { Trigone }\end{array}$ & $60-72$ \\
\hline $5(9,4 \%)$ & Hard Pale & $56-62$ \\
\hline $3(5,66 \%)$ & Oropharynx & $60-72$ \\
\hline $2(3,8 \%)$ & Larynx & 52 \\
\hline $2(3,8 \%)$ & Rhabdomyosarco & $70-72$ \\
\hline $2(3,8 \%)$ & Parotid & $60-66$ \\
\hline $1(1,9 \%)$ & Lip & 66 \\
\hline
\end{tabular}
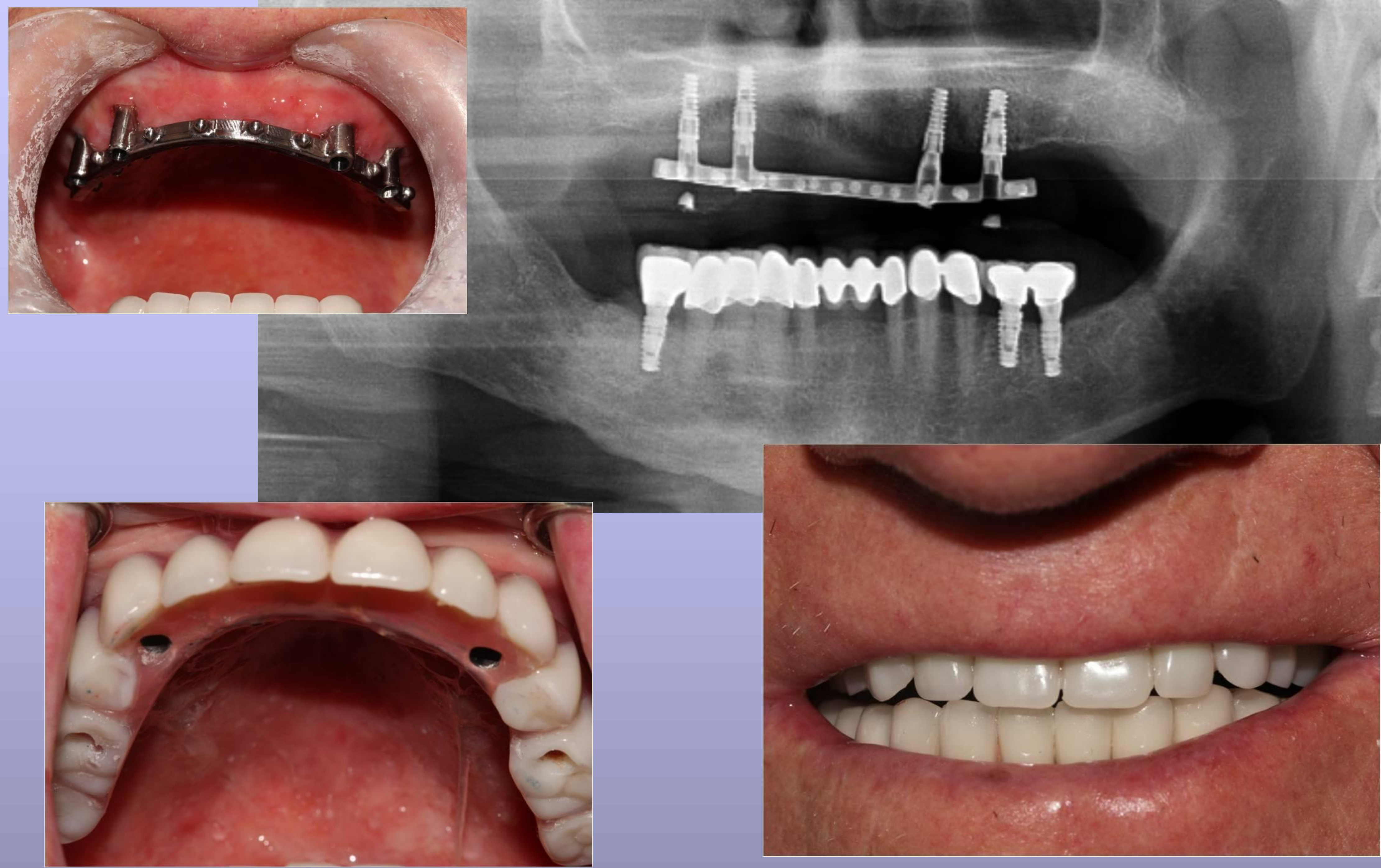

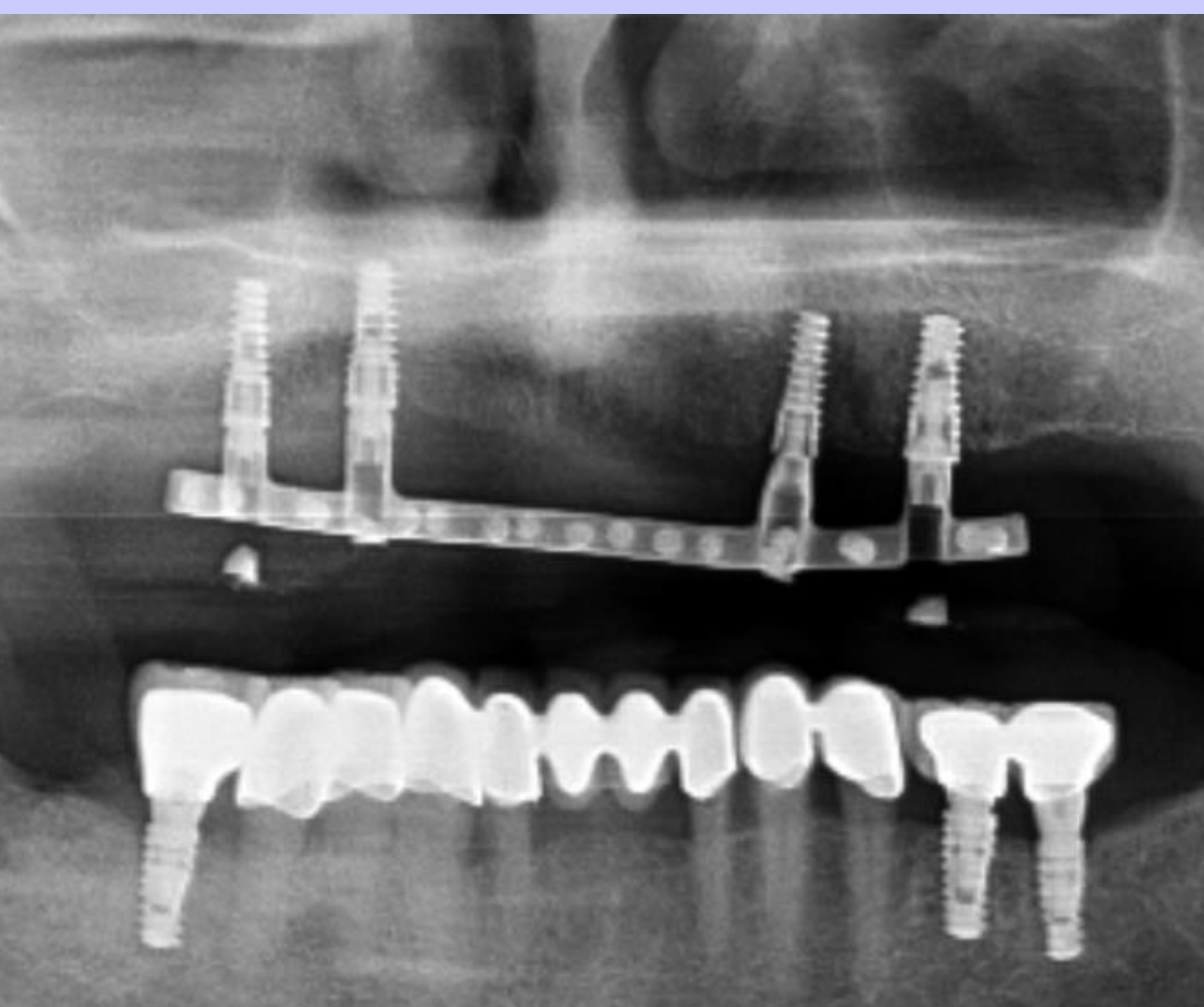

